\title{
Parameter estimation of output power curves for some current small- scale wind turbines
}

\author{
D.D. Fabiane, R. Treméa, J.M.V. Grzybowski \\ Universidade Federal da Fronteira Sul - UFFS \\ Av. Dom João Hoffmann, 313, CEP 99.700-000, Erechim, RS. \\ E-mail: jose.grzybowski@uffs.edu.br
}

\begin{abstract}
The assessment of estimated output energy is a key issue in the design and sizing of wind generation projects. Further, its accuracy and reliability can benefit from the use of actual power curves of wind generators that furnish the response of the generator to the wind regime under consideration. The unavailability of studies of this nature for small-scale wind generation is presumably a limitation for autonomous investments in wind energy. In this paper, we estimate the parameters of the power curves of five small-scale wind generators currently available. The results are presented as analytical performance curves that can be directly used in assessing their power output as subject to a given wind regime, thus providing a practical and straightforward tool for power potential assessment.
\end{abstract}

\section{Introduction}

As properly exploited, wind power can supply a substantial share of the actual load demand of electricity [1][2]. The attractiveness of wind power lies upon zero emission, abundant wind availability, low operational cost and scalability, among others, being suitable for applications ranging from extensive wind farms to residential standalone wind generators. While prospective studies concerning wind power potential usually focus on extensive projects such as wind farms, an alternative direction that considers recent technological advances in the design of small-scale wind generators has pointed towards the importance of microgeneration to reduce the system's dependence upon base load, thus weaving a increasingly decentralized electrical grid [2]. Towards this end, a crucial requirement is the existence of practical data regarding wind energy potential in terms of existing wind regimes and turbines, thus showing how attractive wind energy looks like in a given location.

It is widely known that the prospection of wind sites is a fundamental part of the process of designing a project for wind electricity. Also important, however less mentioned in current studies within the topic, the proper choice of a wind turbine plays a key role in the overall attractiveness of wind generation. It involves the estimation of the wind generators' performances as subject to given wind regimes, and it is important since each different wind generator gives its particular response to wind excitation, which reflects upon the amount of energy it converts into electricity. Surprisingly, very few scientific studies are dedicated to the modeling or the use of output power curves in the assessment of wind energy potential, from which we highlight [3][4].

In this paper, we study the power output curves of five popular small-scale wind generators currently available, on the basis of data from their respective specifications manuals. The output power curve of the wind generators are approximated by a sigmoid-shaped curve with 4 parameters and wind velocity as independent variable in which the parameters shall be estimated to fit the real power output data. As subject to real wind data, the power output curves can be used to evaluate the generators' performances in a given site and wind regime, thus facilitating the sizing of wind energy projects and providing valuable information to the choice of a wind turbine. As contribution of this paper, the results are presented in the form of directly applicable functions that relate output power and wind velocity.

\section{Materials and methods}

The output power curve of a wind generator can be thought of as a function $P(v)$ that gives the output power, in $k W$, as a function of wind velocity, in $\mathrm{m} / \mathrm{s}$. Each wind generator has its own 
power curve whose parameters depend upon the overall characteristics of the wind turbine, such as the size, shape and efficiency of its blades, the efficiency of its generator, among others. The parameters of the output curve $P(v)$ can be estimated from real output data collected during operation and they hold imprinted in their values the combination of the working characteristics of the generator. A schematic model of the role of the output power curve is presented in Figure 1.

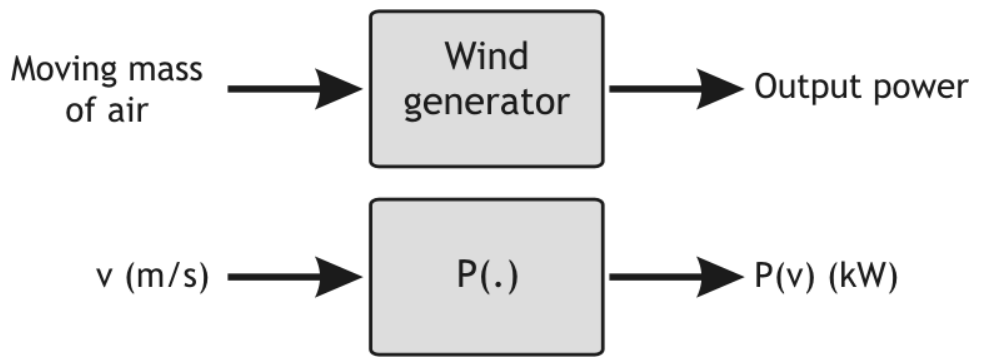

Figure 1 - Scheme of functioning of a wind turbine and the role of the power output curve $\mathrm{P}(\mathrm{v})$

To understand the role of the output power curves of wind generators in the estimation of energy generation, we shall consider further elements involved in the assessment of wind energy potential. Considering the method of bins, as presented in [5], the assessment of wind power potential requires that the wind velocity data are separated into $N$ bins of width $w_{j}$ and midpoints $m_{j}$. The frequency, i.e., the number of occurrences in each bin, is denoted $f_{j}$ and the number of wind velocity readings equals

$$
n=\sum_{j=1}^{N} f_{j}
$$

The long-term average wind power per square meter (in $\mathrm{W} / \mathrm{m}^{2}$ ) is given by

$$
P_{a}=\frac{1}{2 n} \rho \sum_{j=1}^{N} m_{j}^{3} f_{j}
$$

where $\rho$ is the density of air [5]. Note that equation (2) represents the average power available in the moving mass of air per unit area. From the Betz limit [5], recall that the theoretical limit of extractable power from the wind is $16 / 27$ of the total available power, that is,

$$
P_{e}=\frac{16}{54 n} \rho \sum_{j=1}^{N} m_{j}^{3} f_{j}
$$

On its turn, the output power curve of a wind turbine describes how wind velocity relates to output power, and it is obtained from measurement data collected during operation. As a given generator has a output power function $P(v)$, the average wind machine power can be written as

$$
P_{\bar{w}}(v)=\frac{1}{n} \sum_{j=1}^{N} P\left(m_{j}\right) f_{j}
$$

Further, the estimation of the total energy output is obtained by simple multiplication of the average wind power, in equation (4), by the number of hours in a season (for seasonal energy output).

Characteristically, the output power curve of wind generators has a sigmoid-shaped evolution as wind velocity increases from zero, at it can be checked in the experimental output curves presented in references [7][8][9][10]. To model such behavior, the general function

$$
P(v)=\frac{A}{B+C e^{-D v}}
$$

was employed, whose parameters $A, B, C, D$ are estimated. Towards this end, the ouput data of five wind generators is considered and the parameters are estimated by means of the LevembergMarquardt algorithm [6]. The generators considered are XZeres 110 [7], Verne555 [8], Bergey Excel 5 [9], Bergey Excel 10 [10] and XZeres 442SR [7]. Some of their characteristics, as they 
read in their respective specifications' manuals, are presented in Table 1. Further, as the cut-in and cut-out velocities are considered, the power output curve can be represented as a function defined by parts. The comparative of the blade diameters is presented in Figure 2.

\begin{tabular}{|l|r|r|r|r|}
\hline \multicolumn{1}{|c|}{ Generator } & Diameter $(\mathbf{m})$ & Cut-in(m/s) & Cut-out (m/s) & Rated power (kW) \\
\hline XZeres110 & 3.60 & 2.5 & 16.0 & 2.5 \\
\hline Verne 555 & 5.55 & 2.2 & 16.0 & 6.0 \\
\hline Bergey Excel 5 & 6.20 & 2.0 & - & 6.2 \\
\hline Bergey Excel 10 & 7.00 & 2.2 & - & 10.0 \\
\hline XZeres442SR & 7.20 & 2.2 & - & 10.0 \\
\hline
\end{tabular}

Table 1 - General characteristics of the generators. Obtained from [7][8][9][10].

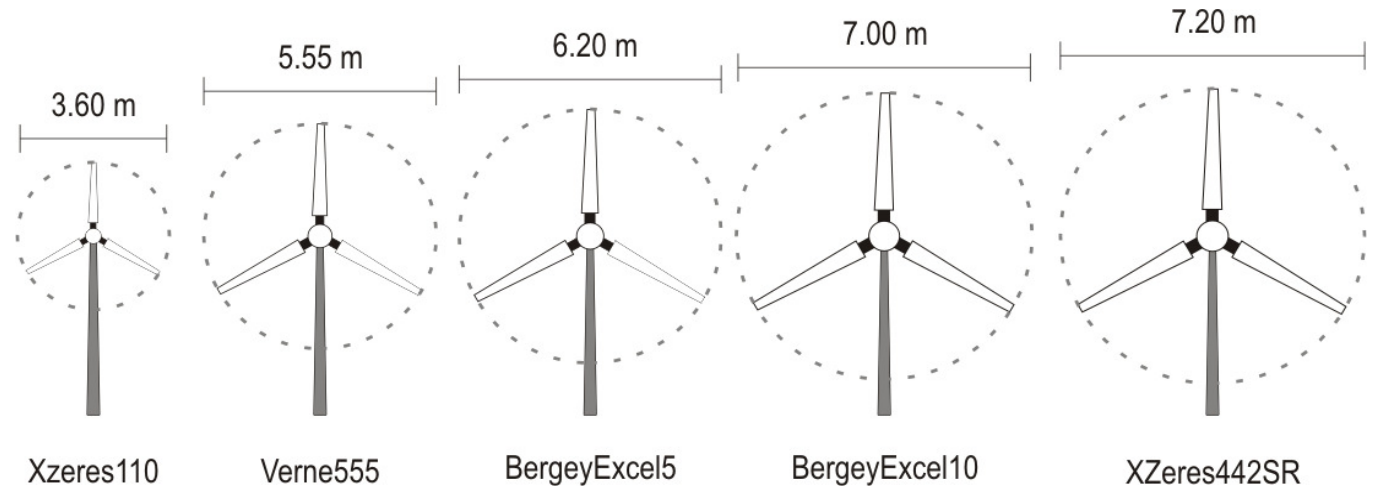

Figure 2 - Comparative sizes of the wind turbines.

\section{Results and discussion}

The resulting curve fittings are shown in Figure 3. The power outputs roughly scale with the generators' diameters, as expected, since power depends on the circular area swept by the generator's blades. Nevertheless, particular characteristics of each generator can be seen as the output power scales with velocity: some of them give a considerably better response as subject to low-to-medium wind velocities, which cannot be completely explained by their diameter. The set of parameters for each curve can be found in the table Table 2 .

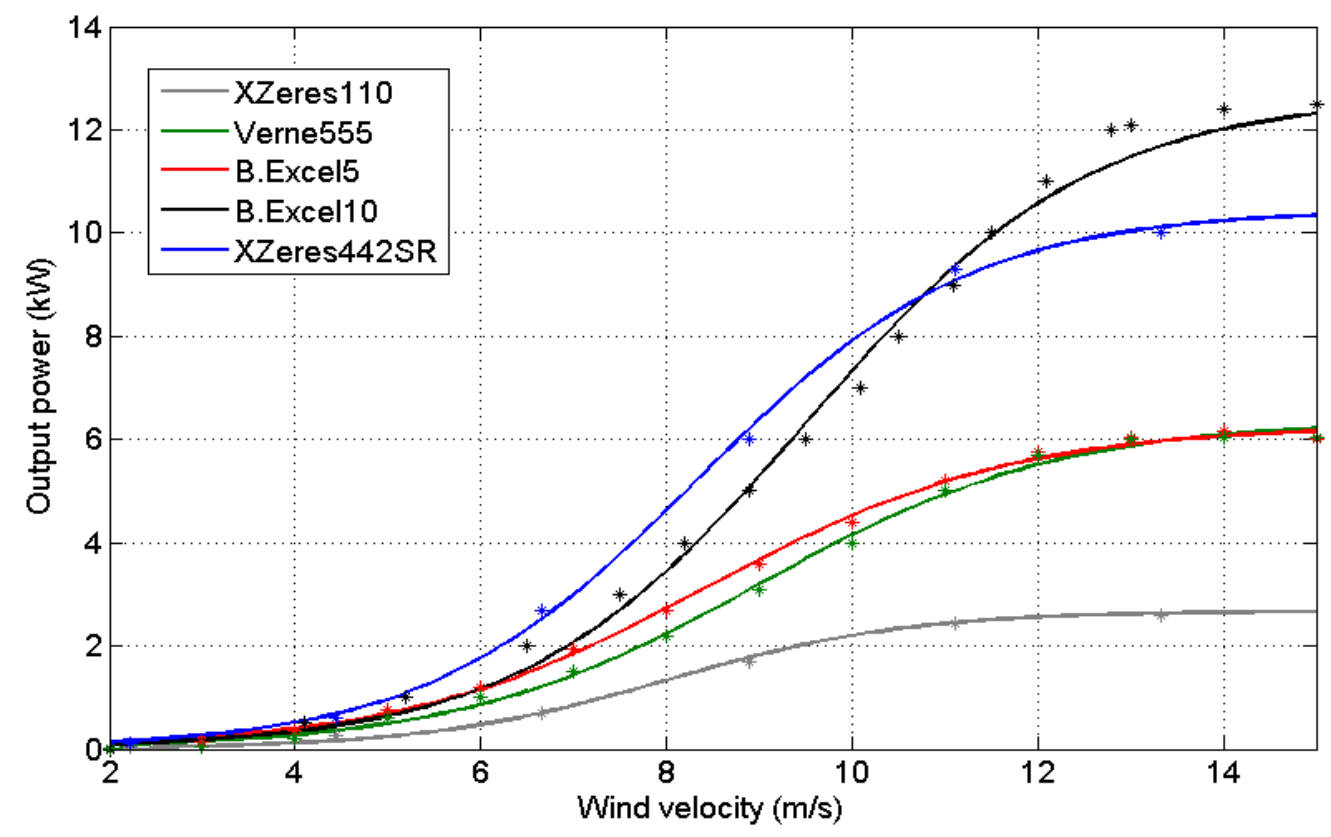

Figure 3 - Estimated power output for the wind turbines. 
The evaluation of performances of different wind generators under the wind regime of a particular site reflects the fact that the specific characteristics of each generator make it respond differently from the others to the same wind regime. Thus, the choice of a proper wind generator for the wind regimes under consideration might be most influential upon the energy outcome. In this regard, it can be exemplified that the generator XZeres442SR [7] featured better performance for winds velocities ranging from 4 to 10 meters per second, while Bergey Excel 10 [10], of almost equivalent size, did better for wind velocities higher than 11 meters per second, which implies that a sensible choice of one over the other would combine the use of power output curves and average wind speed data. The combined curves for the generator XZeres110 [7] as subject to wind data from Erechim, Brazil ( $27^{\circ} 38^{\prime} 02^{\prime \prime} \mathrm{S} 52^{\circ} 16^{\prime} 26^{\prime \prime} \mathrm{W}$ ), during Spring, 2012, are shown in Figure 4 as an example. Note that, as the cut-in and cut-out velocities are considered, the power output curve shall be represented as a function defined by parts. Thus, the equations for the generator XZeres 110 becomes $P(v)$, as in equation (5), for $2.5 \leq v \leq 16.0$ and zero otherwise.

\begin{tabular}{|l|c|c|c|c|}
\hline \multicolumn{1}{|c|}{ Generator } & A & B & C & D \\
\hline XZeres110 & 0.0028615 & 0.0010696 & 0.5005590 & 0.7673150 \\
\hline Verne 555 & 0.0122168 & 0.0019296 & 0.5039023 & 0.6194540 \\
\hline Bergey Excel 5 & 0.0240708 & 0.0038411 & 0.6531523 & 0.6091575 \\
\hline Bergey Excel 10 & 0.0159214 & 0.0012578 & 0.6131234 & 0.6506849 \\
\hline XZeres442SR & 0.0181385 & 0.0017355 & 0.5120665 & 0.6819199 \\
\hline
\end{tabular}

Table 2 - Parameters for the output curve of the generators, obtained by means of the LevembergMarquardt algorithm.

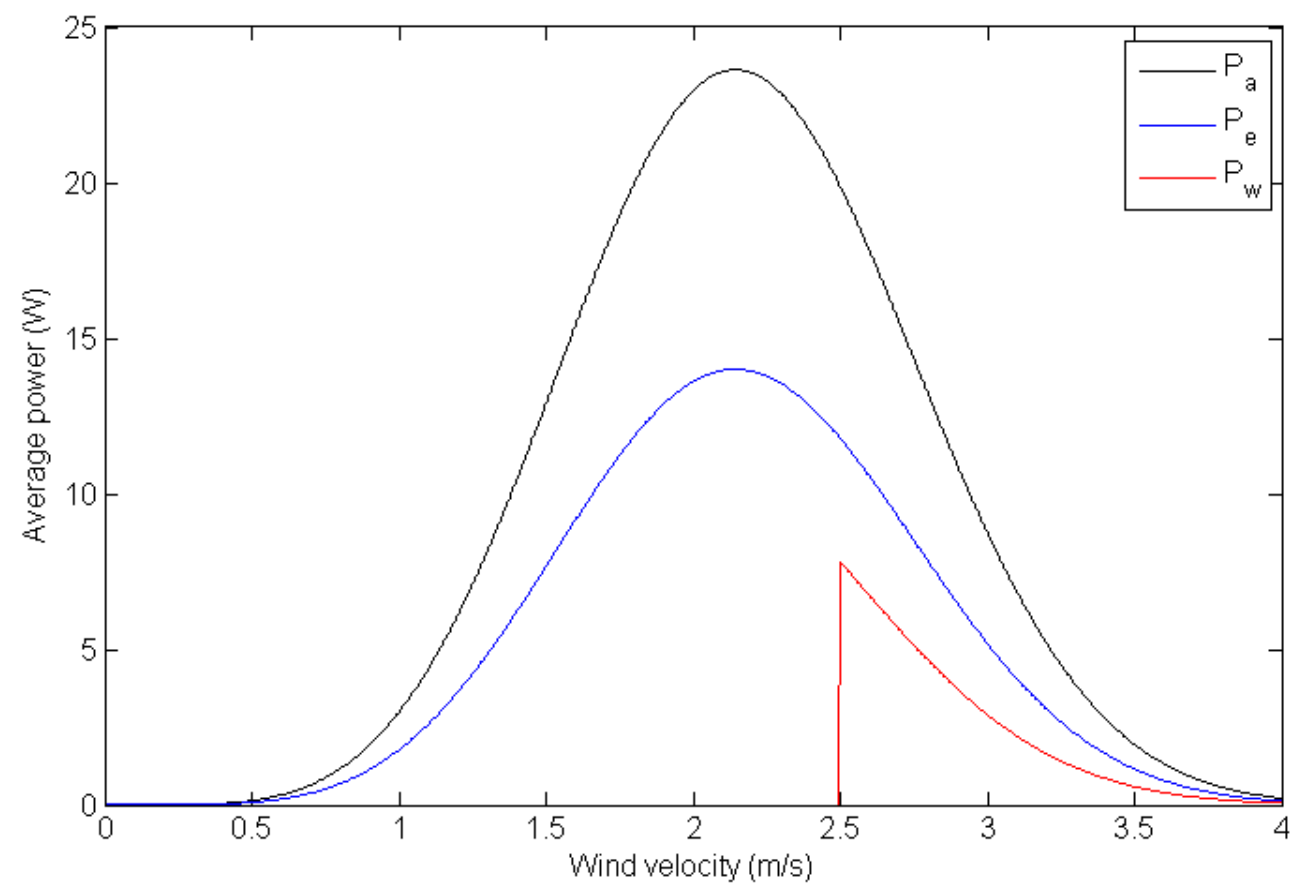

Figure 4 - Averages of available power $\left(P_{a}\right)$, extractable power $\left(P_{e}\right)$ and output power $\left(P_{w}\right)$ for the wind generator XZeres 110 [7] as subject to the wind data from Erechim, Brazil (27³8'02"S $\left.52^{\circ} 16^{\prime} 26^{\prime \prime} \mathrm{W}\right)$, Spring, 2012.

The results presented in this paper are hoped to be useful and support preliminary assessment of power output for autonomous small-scale wind generation projects. The effective use of power output curves of real generators can better the assessment of energy production estimates and qualify the sizing of wind generation projects. As the output power curves considered in this paper are those provided by the manufacturers in the generators' specifications manuals, they shall be subject to testing and confirmation by third parties for accuracy. 
The authors thank CNPq and FAPERGS for the support.

Keywords: Output power curve, small-scale wind turbines, wind potential assessment, parameter estimation.

\section{References}

[1] X. Lu. M.B. McElroy. J. Kiviluoma. Global potential for wind-generated electricity. Proc. National Academy of Science. vol. 106. number 27. pages 10933-10938. (2009).

[2] M.Z. Jacobson. M.A. Delucchi. A path to sustainable energy by 2030. Scientific American. November. pages 58-65. (2009).

[3] A.N. Celik. Energy output estimation for small-scale wind power generators using Weibullrepresentative wind data. Journal of Wind Engineering and Industrial Aerodynamics 91, 693707, 2003.

[4] C. Protogeropoulos, B.J. Brinkworth, R. Marshall. Sizing and techno-economical optimisation for hybrid solar PV-wind power systems with battery storage. International Journal of Energy Resources 21, 1-15, 1997.

[5] J.F. Manwell. J.G. McGowan. A.L. Rogers. Wind energy explained - theory, design and application. John Wiley \& Sons. 2002.

[6] K. Tomczyk. Levenberg-Marquardt algorithm for optimization of mathematical models according to minimax objective function of measurement systems. Metrology and Measurement Systems XVI, number 4, 599-606, 2009.

[7] XZeres Machines Brochure. Available in http://energysmartcompany.com/files/media/xzereswind-turbines/1429-XZERES-Brochure-6-21-2011-Low.pdf.

[8] Aerogerador Verne555: Manual do produto. Available in www.enersud.com.br/wpcontent/.../manual_produtos_verne555_web.pdf. Access in June. 06th. 2013.

[9] Bergey Excel 5 Brochure. Available in http://bergey.com/documents/2012/05/excel-5-specsheet.pdf.

[10] Bergey Excel 10 Brochure. Available in http://bergey.com/documents/2012/05/excel-10brochure.pdf. 